\title{
Mouthpiece Ventilation: Just a Home-Care Support?
}

Noninvasive ventilation (NIV) is recognized nowadays as the first choice of treatment for COPD exacerbation. Compared with standard medical treatment, it can significantly reduce the intubation rate, hospital stay, nosocomial infection, and, above all, mortality rate. ${ }^{1,2}$ Physiological studies have shown that the mechanism of action of NIV in this population is the ability to sustain alveolar ventilation by reducing the work of breathing, ${ }^{3}$ as during

See the Original Study on Page 1825

invasive mechanical ventilation. ${ }^{4}$ For this reason, in COPD exacerbation, NIV may be considered not only the first line of treatment after failure of medical therapy but also, in expert hands and a monitored environment, an alternative to invasive mechanical ventilation. ${ }^{5}$ NIV failure is due mainly to the cause of COPD exacerbation and its severity. ${ }^{6,7}$ However, other clinical and technical situations have been described as possible causes for NIV failure. These include increases in upper airway resistance, sputum retention and/or cough impairment, agitation, mask leakages, and poor mask tolerance. ${ }^{8,9}$ Patient tolerance is often influenced by the shape and fitting of the interface. ${ }^{10,11} \mathrm{It}$ has been suggested that using different masks in the same patient can be helpful in promoting tolerance and comfort. ${ }^{10-13}$ In a particular group of subjects with a do-notintubate order and with a previous NIV trial failure, a change in mask increased the success and hospital discharge rates. ${ }^{14}$

Open-circuit mouthpiece ventilation is a type of NIV delivered via a mouthpiece as interface. It was proposed many years ago in the home-care setting to treat chronic respiratory failure in neuromuscular diseases, especially in North America. ${ }^{15-17}$ The use of mouthpiece ventilation was reported for the first time at a conference on post-poliomyelitis respiratory equipment in $1953 .{ }^{18}$ The author ob-

The authors have disclosed no conflicts of interests.

Correspondence: Annalisa Carlucci MD, Department of Pulmonary Rehabilitation, Fondazione S Maugeri, Istituto di Ricovero e Cura a Carattere Scientifico, Via Maugeri 10, 27100 Pavia, Italy. E-mail: annalisa.carlucci@fsm.it.

DOI: $10.4187 /$ respcare.03789 served that an intermittent positive-pressure ventilator with a mouthpiece circuit could be used to relieve dyspnea in ventilator-dependent polio subjects when switched from negative-pressure ventilation to spontaneous breathing for nursing care or physical therapy.

In subjects who required several hours of ventilatory support, Bach et $\mathrm{al}^{16}$ reported the sequential use of a narrow flexed mouthpiece during the day and a nasal mask during the night. They suggested the possible use of a standard mouthpiece with lip-seal retention or custommolded orthodontic bites for overnight use. In this population of subjects, mouthpiece ventilation use has progressively become a valid alternative to tracheostomy, providing benefits in terms of prevention of respiratory infections, reduction of complications associated with tracheostomy procedure and maintenance, ${ }^{19}$ reduction in swallowing problems, ${ }^{20}$ and improvement in cough, voice, and quality of life. ${ }^{16,21}$

In this issue of Respiratory CARE, Dr Nicolini and colleagues $^{22}$ report an interesting study in which they compared mouthpiece versus nasal mask ventilation to treat COPD exacerbation with mild to moderate acidosis. Subjects were randomly assigned to receive NIV via a nasal mask or mouthpiece. The primary outcome was improvement in arterial blood gases. The 2 groups had similar trends in arterial blood gases and breathing frequency. No differences in duration of NIV or hospital stay were seen. However, a significant difference in tolerance of interface was found: subjects preferred mouthpiece ventilation! The authors concluded that mouthpiece ventilation might be considered as a valid alternative to nasal NIV in mild to moderate COPD exacerbation.

The first questionable point of this article is the comparison with a nasal mask in an acute setting, which is usually not recommended because it leads to mask failure in $>72 \%$ of subjects ${ }^{23}$ and seems to lower $\mathrm{CO}_{2}$ to a lesser extent compared with a facial mask. ${ }^{11,24}$ The application of mouthpiece ventilation in a setting other than neuromuscular disease was tested in 2 previous studies. A physiological study by Fraticelli et al ${ }^{25}$ suggested that a mouthpiece is as effective as a full-face mask in reducing inspiratory effort and improves gas exchanges in subjects receiving NIV for hypercapnic and hypoxic acute respiratory failure. However, this study compared the short-term effects of different interfaces, and conclusions about the long-term tolerance and efficacy of the therapy adminis- 
tered with this interface cannot be made. Some long-term problems may be hypothesized if we consider the reported higher incidence of leaks and asynchronies with a mouthpiece. ${ }^{25}$ A nonrandomized, retrospective, matched casecontrol study compared the use of mouthpiece ventilation with nasal NIV and standard medical treatment in acute respiratory failure with a mean $\mathrm{pH}$ of $7.30 .{ }^{26}$ The study showed that mouthpiece ventilation was as effective as nasal NIV in reducing the rate of intubation. However, once again, the study considered a nasal mask as the reference mask. In the study by Nicolini et al, 22 more severely ill subjects were enrolled $(\mathrm{pH} 7.30-7.25)$ without worsening the outcomes. This probably occurred because there was only one recruiting center, which had acquired experience with mouthpiece ventilation in recent years. We showed that increased years of experience with NIV progressively allowed more severely ill patients to be treated in a less critical environment. ${ }^{27}$

Moreover, we need to consider that mouthpiece ventilation requires a longer learning period then other interfaces, so the need for more cooperative patients and more time spent by nurses and respiratory therapists, at least in the first hours, has to be considered. Finally, some experience with mechanical ventilation is required to use the majority of ventilators, except for a few with software designed for specific mouthpiece ventilation. In fact, the correct setting is required to avoid frequent alarms. ${ }^{28}$

Some limitations must be considered in the study by Nicolini et al. ${ }^{22}$ First, it is a very short-term study. As a matter of fact, it would be of great interest to confirm these results with a longer follow-up. Second, the study is not powered to the primary outcome even for a non-inferiority study. Furthermore, the absence of NIV failure in both groups, which may be related to enrollment bias, is surprising. In fact, as mentioned above, although we reported that NIV experience enabled treatment of more severely ill patients, NIV could not reduce the minimum rate of failure, which is intrinsic to the chronic disease and the cause of COPD exacerbation. ${ }^{27}$

Despite these limitations, the study by Nicolini et al ${ }^{22}$ gives us an important clinical message: mouthpiece ventilation may be considered as another tool in our armamentarium and as an alternative to other interfaces. However, due to its specific features and drawbacks (leaks, etc), it must be managed by an expert hand and in a wellmonitored environment even in moderate COPD exacerbation.

Further clinically powered studies are clearly needed to clarify whether mouthpiece ventilation may represent a safe and effective alternative to NIV delivered by conventional masks. In the next few years, we hope that management of COPD exacerbation will be targeted to a specific approach for each patient in accordance with ethical and final therapeutic goals.

\section{Annalisa Carlucci MD \\ Department of Pulmonary Rehabilitation \\ Fondazione S. Maugeri \\ Istituto di Ricovero e Cura a Carattere Scientifico Pavia, Italy}

Cesare Gregoretti MD

Department of Anesthesia and Intensive Care Città della Salute e della Scienza

Turin, Italy

\section{REFERENCES}

1. Dwarakanath A, Elliott MW. Noninvasive ventilation in the management of acute hypercapnic respiratory failure. Breathe 2013;9(5): 338-348.

2. Elliott M, Ambrosino N: Noninvasive ventilation: a decade of progress. Eur Respir J 2002;19(4):587-589.

3. Brochard L, Mancebo J, Wysocki M, Lofaso F, Conti G, Rauss A, et al. Noninvasive ventilation for acute exacerbations of chronic obstructive pulmonary disease. N Engl J Med 1995;333(13):817-822.

4. Vitacca M, Ambrosino N, Clini E, Porta R, Rampulla C, Lanini B, Nava S. Physiological response to pressure support ventilation delivered before and after extubation in patients not capable of totally spontaneous autonomous breathing. Am J Respir Crit Care Med 2001;164(4):638-641.

5. Squadrone E, Frigerio P, Fogliati C, Gregoretti C, Conti G, Antonelli $\mathrm{M}$, et al. Noninvasive vs invasive ventilation in COPD patients with severe acute respiratory failure deemed to require ventilatory assistance. Intensive Care Med 2004;30(7):1303-1310.

6. Nava S, Hill N. Non-invasive ventilation in acute respiratory failure. Lancet 2009;374(9685):250-259.

7. Confalonieri M, Garuti G, Cattaruzza MS, Osborn JF, Antonelli M, Conti G, et al. A chart of failure risk for noninvasive ventilation in patients with COPD exacerbation. Eur Respir J 2005;25(2):348-355.

8. Schettino G, Altobelli N, Kacmarek RM. Noninvasive positive-pressure ventilation in acute respiratory failure outside clinical trials: experience at the Massachusetts General Hospital. Crit Care Med 2008;36(2):441-447.

9. British Thoracic Society Standards of Care Committee. Non-invasive ventilation in acute respiratory failure. Thorax 2002;57(3):92211.

10. Gregoretti C, Confalonieri M, Navalesi P, Squadrone V, Frigerio P, Beltrame F, et al. Evaluation of patient skin breakdown and comfort with a new face mask for non-invasive ventilation:a multi-center study. Intensive Care Med 2002;28(3):278-284.

11. Nava $S$, Navalesi $P$, Gregoretti C. Interfaces and humidification for non-invasive ventilation. Respir Care 2009;54(1):71-84.

12. Crimi C, Noto A, Princi P, Esquinas A, Nava S. A European survey of non-invasive ventilation practice. Eur Respir J 2010;36(2):362369.

13. Antonelli M, Pennisi MA, Pelosi P, Gregoretti C, Squadrone V, Rocco $\mathrm{M}$, et al. Noninvasive positive pressure ventilation using a helmet in patients with acute exacerbation of chronic obstructive pulmonary disease: a feasibility study. Anesthesiology 2004;100(1): 16-24.

14. Lemyze M, Mallat J, Nigeon O, Barrailler S, Pepy F, Gasan G, et al. Rescue therapy by switching to total face mask after failure of face 


\section{Mouthriece Ventilation: Just a Home-Care Support?}

mask-delivered noninvasive ventilation in do-not-intubate patients in acute respiratory failure. Crit Care Med 2013;41(2):481-488.

15. Bach JR, Alba AS, Bohatiuk G, Saporito L, Lee M. Mouth intermittent positive pressure ventilation in the management of post-polio respiratory insufficiency. Chest 1987;91(6):859-864.

16. Bach JR, Alba AS, Saporito L. Intermittent positive ventilation via mouth as an alternative to tracheostomy for 257 ventilator users. Chest 1993;103(1):174-182.

17. Toussaint M, Steens M, Wasteels G, Soudon P. Diurnal ventilation via mouthpiece: survival in end-stage Duchenne patients. Eur Respir J 2006;28(3):549-555.

18. Affeldt JE. Roundtable conference on poliomyelitis equipment. White Plains, New York: National Foundation for Infantile Paralysis/March of Dimes; 1953.

19. Engoren M, Arslanian-Engoren C, Fenn-Buderer N. Hospital and long-term outcome after tracheostomy for respiratory failure. Chest 2004;125(1):220-227.

20. Feldman SA, Deal CW, Urquhart W. Disturbance of swallowing after tracheostomy. Lancet 1966;1(7444):954-955.

21. Bach JR, Rajaraman R, Ballanger F, Tzeng AC, Ishikawa Y, Kulessa $R$, Bansal T. Neuromuscular ventilatory insufficiency: the effect of home mechanical ventilator use $\mathrm{v}$ oxygen therapy on pneumonia and hospitalization rates. Am J Phys Med Rehabil 1998;77(1):8-19.

22. Nicolini A, Santo M, Ferrari-Bravo M, Barlascini C. Open-mouthpiece ventilation versus nasal mask ventilation in subjects with COPD exacerbation with mild to moderate acidosis: a randomized trial. Respir Care 2014;59(12):1825-1831.

23. Girault C, Briel A, Benichou J, Hellot MF, Dachraoui F, Tamion F, Bonmarchand $\mathrm{G}$. Interface strategy during noninvasive positive pressure ventilation for hypercapnic acute respiratory failure. Crit Care Med 2009;37(1):124-131.

24. Navalesi P, Fanfulla F, Frigerio P, Gregoretti C, Nava S. Physiologic evaluation of noninvasive mechanical ventilation delivered with three types of masks in patients with chronic hypercapnic respiratory failure. Crit Care Med 2000;28(6):1785-1790.

25. Fraticelli AT, Lellouche F, L'her E, Taillé S, Mancebo J, Brochard L. Physiological effects of different interfaces during noninvasive ventilation for acute respiratory failure. Crit Care Med 2009;37(3): 939-945.

26. Glerant JC, Rose D, Oltean V, Dayen C, Mayeux I, Jounieaux V. Noninvasive ventilation using a mouthpiece in patients with chronic obstructive pulmonary disease an acute respiratory failure. Respiration 2007;74(6):632-639.

27. Carlucci A, Delmastro M, Rubini F, Fracchia C, Nava S. Changes in the practice of non-invasive ventilation in treating COPD patients over 8 years. Intensive Care Med 2003;29(3):419-425.

28. Khirani S, Ramirez A, Delord V, Leroux K, Lofaso F, Hautot S, et al. Evaluation of ventilators for mouthpiece ventilation in neuromuscular disease. Respir Care 2014;59(9):1329-1337. 